\title{
Morbidity and mortality of children aged 2-59 months admitted in the Tanzania Lake Zone's public hospitals: a cross-sectional study
}

\author{
Kristina Lugangira ${ }^{1}$, Method Kazaura ${ }^{2^{*}}$ and Festus Kalokola ${ }^{1}$
}

\begin{abstract}
Background: There is a growing concern about child mortality especially in developing countries. The Government of Tanzania and non-governmental organizations are fighting against diseases like malaria, anaemia, diarrhoea and pneumonia that contribute extensively to child mortality. This was a hospital-based, retrospective cohort study involving 1130 under-fives (excluding neonates) being either discharged from or died in public hospitals of the Lake Zone in Tanzania. We extracted information on symptoms and signs at admission, major diagnoses and causes of death from the medical records. We applied binary logistic regression models to assess risk factors associated with in-patient under-five death.

Results: The major leading morbidities include malaria (49\%), anemia (37\%), diarrhea (27\%), pneumonia (22\%) and severe acute malnutrition (21\%). We found the case fatality of 74 deaths per 1000 under-five admissions. Major underlying causes of deaths were severe anaemia, severe malaria and severe pneumonia. Factors associated with in-patient death were female sex (AOR 1.7; 95\% Cl 1.0, 2.8) and the odds significantly decreased with increasing level of maternal education.
\end{abstract}

Conclusions: Malaria remains a leading cause of admissions in hospitals among under-fives. Although the case fatality among children aged between 2 and 59 months admitted in hospitals in Lake Zone is decreasing, efforts are needed to address major causes of deaths (severe anaemia, severe malaria and severe pneumonia).

Keywords: Case-fatality, In-patient, Morbidity, Mortality, Tanzania

\section{Background}

The fourth United Nation's Millennium Development Goal advocated the reduction of under-five death by twothirds between 1990 and 2015 [1]. There are reports of decreasing risks of child mortality globally and in some developing countries, specifically from sub-Saharan Africa including Tanzania [2-5]. Nevertheless, the gap of mortality levels among under-fives between industrialized and the less developed countries is still wide [68]. Major setbacks to reduce infant and child mortality include maternal and child morbidities, for example HIV and other infectious diseases like malaria and diarrhea

\footnotetext{
*Correspondence: mrkazaura@muhas.ac.tz

${ }^{2}$ Department of Epidemiology/Biostatistics, Muhimbili University of Health and Allied Sciences, P. O. Box 65015, Dar es Salaam, Tanzania Full list of author information is available at the end of the article
}

[9-13]. In 2000, the magnitude of under-five mortality in sub-Saharan Africa was estimated at 175 per 1000 livebirths [14].

In Tanzania, the under-five mortality has been decreasing over time. For example, the mortality dropped from 153.6 in 1991/92 to between 50 and 80 per 1000 live births in 2010 [15-17]. Despite the reported decreasing risks, there is variability of under-five mortality between and within regions. For example, in the Lake Zone of Tanzania, the under-five mortality was close to 170 in 1991 and decreased to about 110 per 1000 live births in $2010[15,16]$. These risks are substantially higher than the national estimate.

Causes of under-five mortality are diverse. Literature from sub-Saharan countries indicates the major causes to be diarrhoea, malnutrition, pneumonia, malaria and 
anaemia; meningitis, HIV infection, gastroenteritis/dehydration, septicaemia and tuberculosis; hypoglycaemia and acute lower respiratory tract infection [18-22].

In Tanzania, like in many other developing countries, there is lack of appropriate and accurate data on specific causes of death and associated factors not only among children but also in adults [23, 24]. Also, there are some concerns regarding poor disease management, health management information and registration systems in Tanzania [25]. Correct diagnosis, proper recording and transfer of data especially on specific causes of mortality in under-fives are often not accurate leading to unreliable morbidity and mortality estimates [26].

The Lake Zone has been receiving health care support from the Ministry of Health and Social Services and its development partners. One of these partners is the USAID-supported Tibu Homa Project (THP). The ultimate goal of THP has been to improve the diagnosis and management of severe febrile illness in children under the age of 5 years in the Lake Zone of Tanzania. In this study we aimed to estimate the major causes of in-patient morbidity and case fatality among hospitalized children under the age of 5 years in the Lake Zone.

\section{Methods}

\section{Study design}

This was a hospital-based, retrospective cohort study. Recruitment into the study was conducted between September and November 2015.

\section{Study settings}

The Lake Zone is situated in the North-West of Tanzania along the Lake Victoria. It comprises of six administrative regions, namely Geita, Kagera, Mara, Mwanza, Shinyanga and Simiyu. The Lake Zone has an estimated total population of about 11.8 million (26.3\% of the nation's population) of which about $11.5 \%$ are children below 5 years [16]. By the time of the study, the Zone had a total of 37 Districts (an administrative sub-division of a Region).

In Tanzania, there are public and private health care facilities. The public health care system is layered into five levels, starting with the dispensary level, the health centre, the district, regional and topped with zonal referral hospitals. These levels are differentiated by the staffing, equipment and supplies, range of services available and type and number of patients eligible for admission. Everywhere in Tanzania, including the Lake Zone hospitals, district and regional hospitals are considered referral facilities; getting patients from the lower levels (Health Centres and Dispensaries).

For the purpose of this study, the focus was on three regions (Kagera, Mara and Mwanza) that were among the regions supported by the Tibu Homa Project (THP). Therefore, the three regional hospitals were selected. Also included in the study, were three randomly selected district hospitals; one from each region. These were Ngara (Kagera Region), Tarime (Mara Region) and Magu (Mwanza Region). These health facilities are expected to have reliable services and more experienced medical staff, having advanced examination medical services (basic laboratory examinations and X-ray facilities) and improved pharmacies. Therefore, they are in better position to correctly assess causes of deaths than lower health facilities.

\section{Study population}

The study included children aged below 5 years (excluding neonates) hospitalized during the study period. We excluded neonates because in almost all facilities there is lack of neonatal wards and these babies stayed with their mothers in female or maternity wards. We also excluded children who were referred to other facilities because it was not possible to ascertain their treatment outcomes (discharged or died). We collected data among study participants between admission until discharged or death. During the study period, information was retrieved from hospital clinical records and transcribed into study tools.

\section{Sample size and sampling procedure}

We estimated a sample of 1155 children based on cluster sampling. Parameters used during the sample size estimation include child inpatient mortality of 60 per 1000 admissions, $95 \%$ confidence interval and a $2 \%$ margin of error. Furthermore, since the use of cluster sampling does not give equal chance to be selected, we assumed a design effect of 2 . We finally adjusted the sample size taking into account non-response that was estimated to be $6 \%$. This sample was split between six clusters. Clusters were public regional and district hospitals. One district hospital was randomly selected per region to make a total of six hospitals. Public regional and district hospitals are facilities with referral medical services. These health facilities are reliable with experienced medical staff, equipped with examination and medical services, (basic examination laboratories and X-ray facilities) and with stocked pharmacies. Based on the hierarchy, regional hospitals are superior to district hospitals. They have more specialized personnel, surgical medical care, equipment and extended capacity to admit. However, all regional and district hospitals have at least one specialist in paediatrics and they also perform laboratory services.

\section{Recruitment procedure}

Recruitment was at death or discharge of the child when information was collected on diagnosis and cause of 
death. Study information was drawn from case notes after obtaining consent from biological parents or legal caregivers.

\section{Process}

The study personnel who included, three clinicians and a nurse (staff attached to pediatric wards) were identified from the facility. These are care providers who attend children and had been previously trained by Tibu Homa Project in proper diagnosis and treatment of under-fives using national protocols and guidelines. Complete information about signs and symptoms were obtained from parents or caregivers at admission. Present and past medical histories and detailed family histories of all admitted under fives were recorded. All children were assessed for general danger signs and main symptoms according WHO guidelines. Nutritional status information was available for all children at admission. The information was recorded by measuring weight, length and midupper arm circumference and classified using Z-scores. Later on, this information was abridged and compiled for under-fives enrolled to the study.

Specific causes of deaths among children were obtained using patients' clinical notes and from diagnosis made on death certificates. Most of the variables for the child were based on parent/care-givers report using face-toface interviews. For example, age, sex, religion; relationship to the child (parents or kin caretaker), education level attained by the parent/care-giver, marital status and occupation. Education level was classified as "never in school"; "some primary" and "above primary". Occupation was categorized as "salaried", "unemployed", "subsistence farming" and "self-employed/wage earners".

Two independent death auditors reviewed patients' files and death certificates to ascertain the cause of death using International Classification of Disease 10th Revision (ICD-10). Whenever there was no definite cause of death or when there was disagreement between death auditors, the cause of death was considered "unknown".

\section{Data processing and analysis}

We performed double entry of data to verify and minimize random errors so as to enhance quality of data. Then, syntax programmes and univariate analyses were performed to detect and correct inconsistencies and out-of-range values. Detected inconsistencies and outof-range values were set to 'missing. Frequencies were used to get descriptive statistics. We also performed cross-tabulations to assess the associations between case fatality and pre-determined variables. These variables were included based on theory, research experience and empirical evidence. A cut-off point for a statistical significance was set at a $\mathrm{p}$ value of 0.05 . Finally, independent factors for inpatient under-five death were determined using binary logistic regression in the multivariable model, controlling for the cluster design effect. Since under-fives were not completely randomly selected, during the analysis confidence intervals and p-values were based on robust estimation of variance by accounting for clustering of study participants within the same facility and their residence. All these procedures were performed using SPSS for Windows (Version 20).

\section{Results}

\section{Description of under-fives}

A total of 1130 (response rate 97.8\%) study participants were included in the study; the shortfall mainly caused by low admission of under-fives in some district hospitals after the targeted study duration. Male and females were almost equally enrolled (Sex ratio, 100:100.9). Their mean age was $21.1(\mathrm{SD}=14.5)$ months. The majority, 970 (86.5\%), waited at least two days before seeking medical treatment (Table 1).

\section{Description of parents/caregivers}

The majority of accompanying parent/caregiver, 975 (91.9\%) were females; 1043 (95.7\%) being biological parents and 954 (85.2\%) having attained some primary education level and above. Those accompanying the ailing children were relatively young, mean of $28.8(\mathrm{SD}=7.5)$ years (Table 2).

Table 1 Socio-demographic characteristics of children aged 2-59 months admitted in public hospitals in the Lake Zone ( $\mathrm{N}=1130)$

\begin{tabular}{lc}
\hline Characteristic & Number (\%) \\
\hline Source of the sample (region) & \\
Kagera & $382(33.8)$ \\
Mara & $269(23.8)$ \\
Mwanza & $479(42.4)$ \\
Sex of the child & \\
Male & $552(48.8)$ \\
Female & $547(48.4)$ \\
Missing & $31(2.8)$ \\
Age (months) & \\
$2-11$ & $354(31.3)$ \\
$12-23$ & $372(32.9)$ \\
$24-35$ & $191(16.9)$ \\
$36-47$ & $124(11.0)$ \\
$48-59$ & $89(7.9)$ \\
Days before seeking health care & \\
$<2$ & $152(13.5)$ \\
$2-4$ & $747(66.1)$ \\
$5+$ & $223(19.7)$ \\
Missing & $8(0.7)$ \\
\hline
\end{tabular}


Table 2 Background characteristics of parents/caregivers of children aged 2-59 months admitted in public hospitals in the Lake Zone $(\mathrm{N}=1130)$

\begin{tabular}{lc}
\hline Background characteristics & Number (\%) \\
\hline Sex & \\
Male & $86(7.6)$ \\
Female & $975(86.3)$ \\
Missing & $69(6.1)$ \\
Age [mean, (SD)] years & $28.8(\mathrm{SD}=7.5)$ \\
Current marital status & \\
Never married & $51(4.6)$ \\
Married (monogamous) & $827(73.9)$ \\
Married (polygamous) & $139(12.4)$ \\
Other & $102(9.1)$ \\
Education status & \\
Never in school & $166(14.7)$ \\
Some primary & $803(71.1)$ \\
Above primary & $151(13.3)$ \\
Missing & $10(0.9)$ \\
Employment status & \\
Salaried & $778(68.8)$ \\
Unemployed & $213(18.9)$ \\
Subsistence farmer & $70(6.2)$ \\
Self-employed/wage earners & $58(5.1)$ \\
Missing & $11(1.0)$ \\
Relationship to the child & \\
Parent & $1043(92.3)$ \\
Kin or other & $47(4.2)$ \\
Missing & $40(3.5)$ \\
\hline Widow, dvore, separ & \\
\hline
\end{tabular}

${ }^{a}$ Widow, divorce, separate

\section{Morbidities among under-fives}

Parents or caregivers reported on signs and symptoms of the child at admission. The major signs and symptoms that were reported included fever 995 (88.1\%), vomiting 518 (45.8\%), diarrhoea 397 (35.1\%) and cough 384 (34.0\%). The major diagnoses were malaria, 555 (49.1\%), anaemia $420(37.2 \%)$, diarrhoea 305 (27.0\%), pneumonia 249 (22.0\%), and malnutrition 219 (20.5\%). Other reported signs and symptoms and final diagnoses are presented in Table 3. Of the malaria cases, 253 (45.6\%) were also anaemic.

\section{Case fatality among inpatient under-fives (2-59 months)}

During the study period, 84 deaths were recorded. This is equivalent to a case fatality of $74(95 \% \mathrm{CI}=60.0,91.6)$ per 1000 under-five admissions in the hospitals. Case fatality was generally higher among under-five inpatients admitted in district hospitals than those admitted in regional hospitals (Fig. 1). Major underlying causes of death were severe anemia, 25 (29.8\%), severe malaria 24
Table 3 Prevalence of morbidities among children aged 2-59 months admitted in public hospitals in the Lake Zone $(\mathrm{N}=1130)$

\begin{tabular}{lc}
\hline Symptom/diagnosis & Number (\%) \\
\hline Major symptoms & \\
Fever & $995(88.1)$ \\
Vomiting & $518(45.8)$ \\
Diarrhoea & $397(35.1)$ \\
Cough & $384(34.0)$ \\
Difficulty in breathing & $189(43.3)$ \\
Convulsions & $153(36.5)$ \\
Pallor & $75(6.6)$ \\
Body swelling & $49(4.3)$ \\
Abdominal discomfort & $29(2.6)$ \\
Other & $279(24.7)$ \\
Major diagnoses & \\
Malaria & \\
Anaemia & $555(49.1)$ \\
Diarrhoea & $420(37.2)$ \\
Pneumonia & $305(27.0)$ \\
Severe stunting & $249(22.0)$ \\
Moderate acute malnutrition & $219(20.5)$ \\
Urinary tract infections & $150(13.7)$ \\
Severe acute malnutrition & $113(10.0)$ \\
HIV/AIDS & $92(8.4)$ \\
Sickle cell disease & $32(2.8)$ \\
Any other & $13(1.2)$ \\
a One child may have multiple diagnoses. Therefore, here we present \\
overlapping diagnoses & $216(19.1)$ \\
\hline
\end{tabular}

$(28.6 \%)$ and severe pneumonia $22(26.2 \%)$. Other underlying causes of in-patient deaths are presented in Table 4.

\section{Morbidity by survival status}

Significantly more children below the age of 5 years died with major symptoms of difficulty in breathing $(\mathrm{p}=0.007)$ and convulsions $(\mathrm{p}=0.006)$ than among those surviving. However, there were significantly more under-fives diagnosed with anaemia $(\mathrm{p}<0.001)$, pneumonia $(\mathrm{p}=0.009)$ and malnutrition $(\mathrm{p}=0.006)$ among those who died than those who survived. But this was a reverse for urinary tract infections; significantly more surviving under-fives were diagnosed with urinary tract infections than among those who died $(\mathrm{p}=0.001)$ (Table 5).

\section{Factors associated with in-patient death}

In the bivariate analysis, factors that had p-values less than 0.2 were included in the multivariable logistic regression analysis. These include sex of the child, custodian of the child, maternal education, ever hospitalized and promptness to health facility. All these variables were adjusted for location (region). In our analysis, the risk 


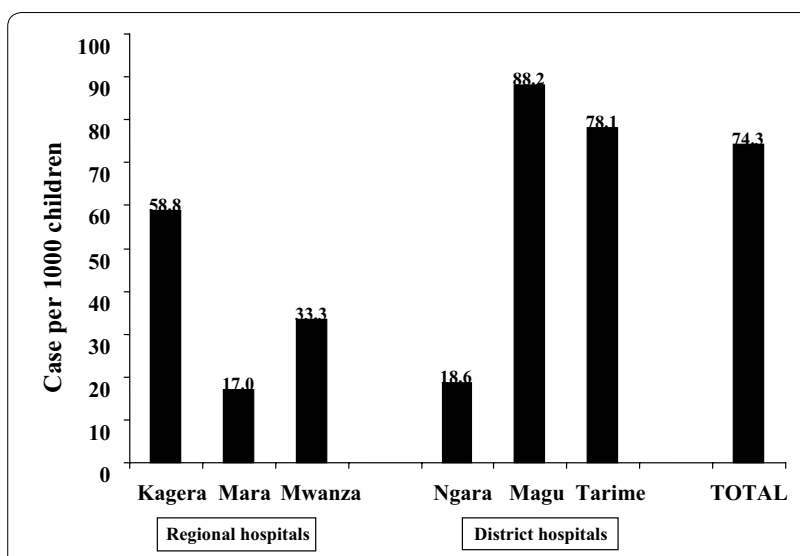

Fig. 1 Case-fatality of children aged 2-59 months admitted in the Lake Zone's public hospitals

Table 4 Major underlying causes of death among children aged 2-59 months admitted in public hospitals in the Lake Zone $(\mathbf{n}=\mathbf{8 4})$

\begin{tabular}{ll}
\hline Cause & Number (\%) \\
\hline Severe anaemia & $25(29.8)$ \\
Severe malaria & $24(28.6)$ \\
Severe pneumonia & $22(26.2)$ \\
Malnutrition & $15(17.9)$ \\
Acute waterly diarrhoea & $14(16.7)$ \\
Other & $10(11.9)$ \\
\hline
\end{tabular}

factors associated with hospital-based in-patient death were sex of the child and maternal education attainment. Females below the age of 5 years had higher odds of deaths than males $(\mathrm{OR}=1.7 ; 95 \% \mathrm{CI}=1.0,2.8)$. Underfives born of mother never in school had increased odds, $(\mathrm{OR}=14.5 ; 95 \% \mathrm{CI}=1.9,111.2)$, as compared to those with above primary education. Similarly, children below the age of 5 years born of mothers with some primary education had increased odds of hospital-based case fatality, $(\mathrm{OR}=11.5 ; 95 \% \mathrm{CI}=1.6,84.0)$, as compared to those with at above primary education (Table 6).

\section{Discussion}

In this paper, we assessed morbidities, case fatality and its associated factors among children under the age of 5 years admitted in public hospitals in the Lake Zone in Tanzania. The five leading major morbidities include malaria (49\%), anaemia (37\%), diarrhoea (27\%) pneumonia (22\%) and severe acute malnutrition (21\%). Many under-five in-patients present with fever, vomiting, diarrhoea and coughing. Previous reports suggest the same leading morbidities among under-fives in developing countries including Tanzania [12, 27-29]. Furthermore, the leading causes of hospital admissions among underfives and adults have been fever, vomiting, diarrhoea and coughing $[3,12,30,31]$.

The prevalence of malaria in this study is extremely high probably due to a high malaria infection during the rainy season (the time we conducted this survey). Also,

Table 5 Differences in morbidities by survival status among children aged 2-59 months admitted in public hospitals in the Lake Zone $(\mathrm{N}=1130)$

\begin{tabular}{lccc}
\hline Symptoms and diagnoses & Survivors $(\%) \mathbf{n = 1 0 4 6}$ & Deaths $(\%) \mathbf{n}=\mathbf{8 4}$ & Difference $(\mathbf{p})^{\mathbf{a}}$ \\
\hline Major symptoms & & & $72(85.7)$ \\
Fever & $923(88.2)$ & $32(38.1)$ & 0.295 \\
Vomiting & $486(46.5)$ & $25(29.8)$ & 0.085 \\
Diarrhoea & $372(35.6)$ & $23(27.4)$ & 0.175 \\
Cough & $361(34.5)$ & $23(27.4)$ & 0.112 \\
Difficulty in breathing & $166(15.9)$ & $20(23.8)$ & 0.007 \\
Convulsions & $133(12.7)$ & & 0.006 \\
Major diagnoses & & $38(45.2)$ & 0.266 \\
Malaria & $517(49.4)$ & $48(57.1)$ & $<0.001$ \\
Anaemia & $372(35.6)$ & $17(20.2)$ & 0.091 \\
Diarrhoea & $288(27.5)$ & $28(33.3)$ & 0.009 \\
Pneumonia & $221(22.0)$ & $28(33.3)$ & 0.006 \\
Malnutrition & $214(20.5)$ & $1(1.2)$ & 0.001 \\
Urinary tract infections & $112(10.7)$ & $4(4.8)$ & 0.209 \\
HIV & $28(2.7)$ & & \\
\hline
\end{tabular}

\footnotetext{
a $p$ values based on Pearson's Chi square test
} 


\begin{abstract}
Table 6 Multivariable binary logistic regression model examining factors associated with case fatality among children aged 2-59 months admitted in public hospitals in the Lake Zone $(\mathrm{N}=1130)$
\end{abstract}

\begin{tabular}{|c|c|c|c|}
\hline \multirow[t]{2}{*}{ Explanatory factors } & \multirow[t]{2}{*}{ Death rate ${ }^{b}$} & \multicolumn{2}{|l|}{ OR $(95 \% \mathrm{Cl})^{a}$} \\
\hline & & Unadjusted & Adjusted $^{\mathrm{c}}$ \\
\hline \multicolumn{4}{|l|}{ Sex of the child } \\
\hline Male & 54.3 & Reference & Reference \\
\hline Female & 91.4 & $1.7(1.0,2.8)$ & $1.7(1.0,2.8)$ \\
\hline \multicolumn{4}{|l|}{ Child's custodian } \\
\hline Both parents & 69.4 & Reference & Reference \\
\hline One/other & 105.9 & $1.6(0.9,2.8)$ & $1.3(0.7,2.5)$ \\
\hline \multicolumn{4}{|l|}{ Maternal education } \\
\hline Never in school & 96.4 & $16.0(2.1,122.2)$ & $14.5(1.9,111.2)$ \\
\hline Some primary & 79.7 & $13.0(1.8,94.4)$ & $11.5(1.6,84.0)$ \\
\hline Above primary & 6.6 & Reference & Reference \\
\hline \multicolumn{4}{|l|}{ Ever hospitalized } \\
\hline Yes & 47.8 & Reference & Reference \\
\hline Never & 86.3 & $1.8(1.1,3.2)$ & $1.6(0.9,2.9)$ \\
\hline \multicolumn{4}{|c|}{ Reported time before seeking health care ${ }^{d}$} \\
\hline Early $(\leq 24 \mathrm{~h})$ & 48.1 & Reference & Reference \\
\hline Late (> 24 h) & 92.0 & $2.0(1.2,3.3)$ & $1.6(0.9,2.7)$ \\
\hline
\end{tabular}

a Odds Ratio (95\% confidence interval)

b Per 1000 under-fives admissions

c Adjusted for location (region)

d Self-reporting of time interval between onset of illness and presenting to health facility

the high prevalence maybe explained by hospital data that are more likely to over-estimate the prevalence.

Despite the decline in mortality, major underlying causes of in-patient death risks in this study were severe anaemia, severe malaria and severe pneumonia. Data from subSaharan and Asian countries indicate malaria, diarrhoea, pneumonia, anaemia and malnutrition as some of the major causes of deaths among children below the age of 5 years $[3,18,32,33]$. However, severe anaemia as a cause of death from this study may be linked with severe malaria.

Our results show females having increased odds of in-patient case fatality than their male counterparts. The differences in mortality by sex between developed and developing countries has not been studied and the link between mortality and sex has not been fully established anywhere. But in Uganda, the Demographic and Health Survey reported females under the age of 5 years as having an advantage of survival over males [34]. If the reported reason of culture in viewing a girl as a source of wealth, this could be the opposite from the study area that considers inheritance of family wealth by males and patrilineage to perpetuate the family's name.

\section{Limitations}

This study has several potential limitations. First, on the one hand this was a hospital-based study with a high possibility of selectivity bias because under-fives presenting to hospitals is dependent on health seeking behavior of the parent/caregiver. In turn, this is likely to over-state the mortality level in the study area. On the other hand, exclusion of neonates in the in-patient children aged below 5 years may have under-stated the level of mortality. Nevertheless, one among other advantages of the study is to confirm the diagnoses that may be relevant for control of diseases. Second, face-to-face interviews were used rather than a self-administered tool. In using this technique, it is possible to introduce information bias because respondents might have been offering socially desirable answers. Third, multiple diagnoses of morbidities that were likely to happen in our study, may not precisely show the distribution of morbidities among study participants. Fourth, although the study tried to examine independent factors associated with case fatality, the selected factors were not exhaustive and missed several social factors such as socio-economic and cultural characteristics that may be related to mortality. Also, asking about past events relies on respondent's memory which may be flawed. Therefore, recall bias cannot be ruled out.

\section{Conclusions}

The current study offers quality data on hospital diagnoses and deaths based on improved diagnoses and treatment of under-fives in the Lake Zone. While malaria remains a leading cause of admissions in hospitals among study participants in this study, the majority have other morbidities that include anemia, pneumonia, diarrhea diseases and malnutrition. In this study, the facilitybased in-patient case-fatality is 74 per 1000 under-five admissions. The major underlying causes of deaths are severe anemia, severe malaria, severe pneumonia and malnutrition. Factors associated with mortality are maternal education and females under the age of 5 years have increased odds of case fatality than their male counterparts.

Results from this study suggest that there is need to revised interventions to address causes of deaths in children aged below 5 years in the Zone. Also, more data are required to further assess the variations in causes of under-five deaths in the Lake Zone.

\section{Abbreviations}

AOR: Adjusted Odds Ratio; Cl: confidence interval; HIV: Human Immunodeficiency Virus; OR: Odds ratio; SD: standard deviation; THP: Tibu Homa Project; USAID: United States Agency for International Development; WHO: World Health Organization. 


\section{Authors' contributions}

$\mathrm{KL}$ and FK: Participated in conception of the study. KL, MK and FK: Designed the study. KL and MK: Participated in data collection and analysis. FK: Gave technical advice. KL, MK and FK: Critically reviewed. All authors read and approved the final manuscript.

\section{Author details}

${ }^{1}$ Department of Case Management, Tibu Homa Project, URC, P. O. Box 1403, Mwanza, Tanzania. ${ }^{2}$ Department of Epidemiology/Biostatistics, Muhimbili University of Health and Allied Sciences, P. O. Box 65015, Dar es Salaam, Tanzania.

\section{Acknowledgements}

We thank the Hospitals' management staff for permission to undertake the study and we thank the parents/caregiver who consented to participate in the study.

\section{Competing interests}

The authors declare that they have no competing interests.

\section{Availability of data and materials}

Although data from this study were collected based on consenting parents/ caregivers and assured them of confidentiality, we did not alert them for possible sharing of data by the third party. Therefore, it may not be possible to make these data a public consumable. However, data may be requested for sharing by writing from the first author (klugangira@yahoo.com).

\section{Consent to publish}

The article does not present details, images, or any visualization of individual participants, therefore consent to publish was not required.

\section{Ethics approval and consent to participate}

Ethical clearance was obtained from the Lake Zone Ethical Review Board (LZERB) and the University Research Company, LLC institutional Review BoardLLC (IRB-URC-Bethesda). Permission to conduct the study was sought from Regional and District Medical Officers (RMO and DMO respectively). Approved by the Review Board, verbal informed consent for children to participate in the study was requested from the biological parents or caregivers accompanying the child during hospitalization. We asked for permission to access medical records and use information obtained only for the purpose of the study. Every parent/caregiver was assured of strict confidentiality such that no information regarding the child or the parent/caregiver will be disclosed to anyone outside the study team.

\section{Funding}

The study was supported by the United States Agency for International Development (USAID) under the terms of Cooperative Agreement Number 621-A-00-11-0011-00.

\section{Publisher's Note}

Springer Nature remains neutral with regard to jurisdictional claims in published maps and institutional affiliations.

Received: 30 August 2016 Accepted: 30 September 2017 Published online: 10 October 2017

\section{References}

1. United Nations. The millennium development goals report 2011. New York: UNO; 2011.

2. You D, Hug L, Ejdemyr S, Idele P, Hogan D, Mathers C, et al. United Nations Inter-agency Group for Child Mortality Estimation (UN IGME). Global, regional, and national levels and trends in under-5 mortality between 1990 and 2015, with scenario-based projections to 2030: a systematic analysis by the UN Inter-agency Group for Child Mortality Estimation. Lancet. 2015;386(10010):2275-86. doi:10.1016/ S0140-6736(15)00120-8

3. Kanté AM, Nathan $\mathrm{R}$, Helleringer S, Sigilbert M, Levira F, Masanja $\mathrm{H}$, et al. The contribution of reduction in malaria as a cause of rapid decline of under-five mortality: evidence from the Rufiji Health and Demographic Surveillance System (HDSS) in rural Tanzania. Malar J. 2014;10(13):180. doi:10.1186/1475-2875-13-180.

4. Kabudula CW, Tollman S, Mee P, Ngobeni S, Silaule B, Gómez-Olivé F, et al. Two decades of mortality change in rural northeast South Africa. Global Health Action. 2014. doi:10.3402/gha.v7.25596.

5. Bhutta ZA, Chopra M, Axelson H, Berman P, Boerma T, Bryce J, et al. Countdown to 2015 decade report (2000-10): taking stock of maternal, newborn, and child survival. Lancet. 2010;375(9730):2032-44. doi:10.1016/ S0140-6736(10)60678-2

6. Amouzou A, Kozuki N, Gwatkin DR. Where is the gap? The contribution of disparities within developing countries to global inequalities in under-five mortality. BMC Public Health. 2014;1(14):216. doi:10.1186/1471-2458-14-216.

7. Nguyen $\mathrm{KH}$, Jimenez-Soto E, Dayal P, Hodge A. Disparities in child mortality trends: what is the evidence from disadvantaged states in India? The case of Orissa and Madhya Pradesh. Int J Equity Health. 2013;27(12):45. doi:10.1186/1475-9276-12-45.

8. Gwatkin DR, Rutstein S, Johnson K, Suliman E, Wagstaff A, Amouzou A. Socio-economic differences in health, nutrition and population within developing countries: an overview. Washington D.C: The World Bank; 2007.

9. Rumisha SF, Smith TA, Masanja H, Abdulla S, Vounatsou P. Relationship between child survival and malaria transmission: an analysis of the malaria transmission intensity and mortality burden across Africa (MTIMBA) project data in Rufiji demographic surveillance system, Tanzania. Malar J. 2014:28(13):124 doi:10.1186/1475-2875-13-124.

10. Nataro JP. Diarrhea among children in developing countries. Adv Exp Med Biol. 2013;764:73-80.

11. Levine MM, Kotloff KL, Breiman RF, Zaidi AK. Diarrheal disease constitutes one of the top two causes of mortality among young children in developing countries. Preface. Am J Trop Med Hyg. 2013;89(1 Suppl):1-2. doi:10.4269/ajtmh.12-0748.

12. Black RE, Cousens S, Johnson HL, Lawn JE, Rudan I, Bassani DG, et al. Global, regional, and national causes of child mortality in 2008: a systematic analysis. Lancet. 2010;375(9730):1969-87.

13. Stanecki K, Daher J, Stover J, Akwara P, Mahy M. Under-5 mortality due to HIV: regional levels and 1990-2009 trends. Sex Transm Infect. 2010;86(Suppl 2):ii56-61. doi:10.1136/sti.2010.046201.

14. UNICEF. Levels \& trends in child mortality. 2014. Accessed 15 Aug 2016.

15. National Bureau of Statistics (NBS) [Tanzania] and ORC Macro. Tanzania Demographic and Health Survey 1991-1992. Dar es Salaam;1993.

16. National Bureau of Statistics (NBS) [Tanzania] and ICF Macro. Tanzania Population and Housing Census 2012. Dar es Salaam; 2014.

17. United Nations Children's Fund (UNICEF). Levels \& Trends in Child Mortality Report 2015, September 2015.

18. Tette EM, Neizer M, Nyarko MY, Sifah EK, Nartey ET, Donkor ES. Changing patterns of disease and mortality at the Children's Hospital, Accra: are infections rising? PLoS ONE. 2016;11(4):e0150387. doi:10.1371/journal. pone.0150387.eCollection.

19. Nantanda R, Ostergaard MS, Ndeezi G, Tumwine JK. Clinical outcomes of children with acute asthma and pneumonia in Mulago hospital, Uganda: a prospective study. BMC Pediatr. 2014;28(14):285. doi:10.1186/ s12887-014-0285-4

20. Kesteman T, Randrianarivelojosia M, Mattern C, Raboanary E, Pourette D, Girond F, et al. Nationwide evaluation of malaria infections, morbidity, mortality, and coverage of malaria control interventions in Madagascar. Malar J. 2014;13:465. doi:10.1186/1475-2875-13-465.

21. van den Boogaard W, Manzi M, Harries AD, Reid AJ. Causes of pediatric mortality and case-fatality rates in eight Médecins Sans Frontièressupported hospitals in Africa. Public Health Action. 2012;2(4):117-21. doi:10.5588/pha.12.0038

22. Stekelenburg J, Kashumba E, Wolffers I. Factors contributing to high mortality due to pneumonia among under-fives in Kalabo District. Zambia. Trop Med Int Health. 2002;7(10):886-93.

23. Lawn JE, Cousens S, Zupan J. 4 Million neonatal deaths: when? Where? Why? The Lancet. 2005;365(9462):891-900

24. Kahn K, Tollman SM, Garenne M, Gear JSS. Who dies from what? Determining cause of death in South Africa's rural north-east. Tropl Med Int Health. 1999:4(6):433-41. 
25. Nyamtema AS. Bridging the gaps in the Health Management Information System in the context of a changing health sector. BMC Med Inform Decis Mak. 2010;10:36. doi:10.1186/1472-6947-10-36.

26. Roberts B, Morgan OW, Sultani MG, Nyasulu P, Rwebangila S, Myatt M, et al. A new method to estimate mortality in crisis-affected and resourcepoor settings: validation study. Int J Epidemiol. 2010;39(6):1584-96. doi:10.1093/ije/dyq188.

27. Msangeni HA, Kamugisha ML, Sembuche SH, Malecela EK, Akida JA, Temba FF, et al. Prospective study on severe malaria among in-patients at Bombo regional hospital, Tanga, north-eastern Tanzania. BMC Infect Dis. 2011;11:256. doi:10.1186/1471-2334-11-256.

28. Dillip A, Hetzel MW, Gosoniu D, Kessy F, Lengeler C, Mayumana I, et al. Socio-cultural factors explaining timely and appropriate use of health facilities for degedege in south-eastern Tanzania. Malar J. 2009;8:144

29. Nsimba SE, Massele AY, Eriksen J, Gustafsson LL, Tomson G, Warsame M. Case management of malaria in under-fives at primary health care facilities in a Tanzanian district. Trop Med Int Health. 2002;7:201-9.

30. Ministry of Health and Social Welfare. Health management information System report of 2010. Dar es Salaam: Ministry of Health and Social Welfare; 2010
31. Ministry of Health and Social Welfare. Health Management Information System Report of 2009. Dar es Salaam: Ministry of Health and Social Welfare; 2009

32. Mashoto KO, Malebo HM, Msisiri E, Peter E. Prevalence, one week incidence and knowledge on causes of diarrhea: household survey of under-fives and adults in Mkuranga district, Tanzania. BMC Public Health. 2014;22(14):985. doi:10.1186/1471-2458-14-985.

33. Morris SS, Black RE, Tomaskovic L. Predicting the distribution of under-five deaths by cause in countries without adequate vital registration systems. Int J Epidemiol. 2003;32:1041-51.

34. Nasejje JB, Mwambi HG, Achia TNO. Understanding the determinants of under-five child mortality in Uganda including the estimation of unobserved household and community effects using both frequentist and Bayesian survival analysis approaches. BMC Public Health. 2015;15:1003. doi:10.1186/s12889-015-2332-y.

\section{Submit your next manuscript to BioMed Central and we will help you at every step:}

- We accept pre-submission inquiries

- Our selector tool helps you to find the most relevant journal

- We provide round the clock customer support

- Convenient online submission

- Thorough peer review

- Inclusion in PubMed and all major indexing services

- Maximum visibility for your research

Submit your manuscript at www.biomedcentral com/submit 